\title{
Оптимизация режимов эпитаксиального синтеза структур с квантовыми точками для фотоприемников и солнечных элементов
}

\author{
А.П. Коханенко, К.А. Лозовой, Р.М.Х. Духан, В.В. Дирко, А.В. Войцеховский \\ Национальньй исследовательский Томский государственный университет, Томск, \\ 634050, пр. Ленина, 36 \\ тел:+7 (382) 241-3517, факс:+7 (382) 241-2772, эл. почта: $\underline{\text { ka@ sibmail.com }}$
}

DOI 10.34077/RCSP2019-107

Одним из самых перспективных путей увеличения эффективности солнечных элементов является использование германиевых квантовых точек на кремниевых подложках. В таких структурах формируется так называемая промежуточная зона - область разрешенных состояний в запрещенной зоне кремния. Поэтому становится возможным двухступенчатый переход носителей из валентной зоны в зону проводимости через промежуточную зону, вызванный поглощением низкоэнергетических фотонов. В результате наблюдается продление спектра чувствительности солнечного элемента в длинноволновую область и соответствующее увеличение эффективности преобразования солнечной энергии. Кроме того, достоинством структур с квантовыми точками $\mathrm{Ge} / \mathrm{Si}$ (гетероструктур II типа) является большое время жизни носителей, обусловленное непрямыми оптическими переходами и пространственным разделением электронов и дырок $[1,2]$.

Фотодетекторы с квантовыми точками германия в кремнии также привлекают большое внимание исследователей благодаря совместимости с хорошо развитой кремниевой технологией, работе в диапазоне длин волн прозрачности атмосферы, а также потенциально высокой чувствительности. Однако для реализации всех потенциальных возможностей фотодетекторов и солнечных элементов на основе наноструктур с квантовыми точками германия в кремнии необходима тщательная отработка технологии их синтеза $[3,4]$.

В данной работе проводится анализ перспектив дальнейшего использования наногетероструктур с квантовыми точками германия на кремнии в различных оптоэлектронных устройствах, таких как, например, солнечные элементы и фотоприемники видимого и инфракрасного диапазонов. С использованием комплексной математической модели, позволяющей рассчитать зависимости параметров выращиваемых методом молекулярно-лучевой эпитаксии массивов самоформирующихся наноостровков германия-кремния от условий роста, потоков осаждаемых материалов, состояния подложки теоретически оценены ростовые параметры, необходимые для синтеза таких приборноориентированных гетероструктур. Произведен расчет темнового тока и обнаружительной способности для реальных фоточувствительных структур с квантовыми точками германия на кремнии. Оценены темновые токи в таких структурах, вызванные тепловой эмиссией и барьерным туннелированием носителей, а также обнаружительная способность фотоприемника в приближении ограничений генерационно-рекомбинационными шумами. Показано, что при выборе для параметров модели (в том числе расстояния между энергетическими уровнями и дисперсии этих расстояний от точки к точке, определяемой разбросом островков в массиве по размерам) значений, соответствующих экспериментальным исследованиям морфологии и энергетической структуры рассматриваемых образцов, результаты моделирования хорошо соответствуют экспериментальным данным.

Особое внимание также уделяется теоретической оценке режимов роста для создания ансамблей островков требуемого размера и высокой плотности, с заданными положениями дискретных энергетических уровней и промежуточной зоны для создания солнечных элементов на их основе.

Исследование выполнено при финансовой поддержке РФФИ в рамках научного проекта № 18-3220082.

\section{Лumepamypa}

[1] Liu Z. et al. // Appl. Phys. Lett. 2013. V. 103. P. 082101.

[2] Okada Y. et al. // Appl. Phys. Rev. 2015. V. 2. P. 021302.

[3] Yakimov A.I. et al. // J. Appl. Phys. 2017. V. 122. P. 133101.

[4] Izhnin I.I. et al. // Opto-Electron. Rev. 2018. V. 26. P. 195-200. 